\title{
The Role of Achievement Emotions to Cognitive Load
}

\author{
Sugiyo', Sunawan², Yuli Kurniawati Sugiyo Pranoto ${ }^{3}$ \\ ${ }^{1,2,3}$ Faculty of Education, Universitas Negeri Semarang, Indonesia \\ ${ }^{2}$ Corresponding author: sunawan@mail.unnes.ac.id
}

\begin{abstract}
The purpose of present study was to identify the impact of university students' achievement emotions on cognitive load during attending statistics class. Three hundred and thirty-nine students of statistics classes from various department in Universitas Negeri Semarang, Indonesia, were involved in this survey. Three type of achievement emotion were assessed using Academic Emotions Questionnaire (AEQ) and three type of cognitive load were assessed using Cognitive Load Scale (CLS). The results of present study showed that achievement emotion predicted cognitive load. Specifically, after controlled gender and students' study period, enjoyment positively predicted germane and intrinsic load, boredom positively predicted intrinsic and extraneous load, whereas anxiety predicted intrinsic and germane load. Findings of present study exert the impact of emotions on cognitive load.
\end{abstract}

Keywords: Cognitive Load, Achievement Emotions

\section{Introduction}

During learning, students' cognitive processes complex information. Working memory are facing information to be processed so that the information can be store at long term memory. The capacity of working memory, is discussed in cognitive load theory (J. Sweller, 2005). Further, cognitive load has most important contribution for learning and performance (R.C. Clark, et al, 2006).

In term of extending the cognitive load theory, Brunken, Plass and Moreno (2010) suggested that the construct of cognitive load needs to be investigated by involving noncognitive factor, such as the construct of motivation, affection, and learning process, to enrich the discussion and application of cognitive load theory. In line with their suggestions, the present study intended to clarify the role of achievement emotions on cognitive load during classroom learning.

Achievement emotions were identified to have impact on cognitive load. A study from Chen and Chang (2009) in English learning context showed that anxiety positively predicted cognitive load. Fraser, Ma, Teteris, Baxter, Wright, and Mc Loughlin (K. Fraser, et al, 2012) exerted that positive emotions negatively predicted cognitive load, whereas negative emotions positively predicted cognitive load.

Unfortunately, those two findings assessed cognitive load as a single construct. More recent studies indicated that achievement emotions had significant contribution on cognitive load both in hypermedia (Sunawan, et al, 2017) and classroom learning environment (Sunawan, \& J. Xiong, 2016).

Unfortunately, those two studies indicated inconsistency prediction of negative emotion on each type of cognitive load, whereas positive emotion (i.e enjoyment) consistently predict germane load. Present study was oriented to clarify the role of achievement emotions (specifically enjoyment, boredom and anxiety) to three type of cognitive load by controlling gender and participants' semester period. Findings of this study is expected can affirm the role of achievement emotions to each type of cognitive load.

Cognitive load theory focuses on performance of working memory during processing information. Paas, Van Gog and Sweller (F. Paas, T. Van Gog, and J. Sweller, 2010) defined cognitive load as the number of element information which needs to be processed in working memory before commencing meaningful learning. Students experience cognitive load when there are so many information required to be processed in working memory.

Working memory only capable to process the limited information. The more complex and higher element interactivity of information leads to higher cognitive load. The cognitive load consists of three types, namely, intrinsic load, extraneous load, and germane load (J. Sweller, 2010a \& 2010b). Intrinsic load is related to the complexity of information element that needs to be processed. Extraneous load is related to irrelevant element of 
information with learning activity which is processed in working memory.

In classroom learning environment, irrelevant information comes from the learning media, teachers' teaching methods, the format of information, and the organization of learning contents. Finally, germane load is related to learners' effort devoted to process the element of information so that the information becomes meaningful knowledge.

Intrinsic load and extraneous load are addictive (J. Sweller, 2010a). These means when the level of intrinsic load and extraneous load are high, the capacity of working memory decreases. In opposite, when the levels of intrinsic and extraneous load are low, working memory have more capacity to be allocated to process the other information. As implication in learning context, the intrinsic load needs to be managed so that the complexity level of information can be effectively processed, the extraneous load needs to be reduced, and germane load needs to be encouraged.

Emotions, motivation and cognition factors interact to affect learning process and students' learning performance. In control-value theory of achievement emotions, Pekrun (2006) defined emotion as multi-component, coordinated processes of psychological subsystems including affective, cognitive, motivational, expressive, and peripheral physiological processes.

Further, Pekrun divided emotions into two types, namely activity emotions and outcome emotions. Activity emotions are emotions which occurred during learning process, whereas outcome emotions are emotions which related with the prediction of learning outcomes (prospective outcome emotions) or emotions which related with the accomplished learning outcomes (retrospective outcome emotions). Including activity emotions are enjoyment, anger, frustration, and boredom. Prospective outcome emotions consist of anticipatory joy, hope, hopeless, and anxiety, whereas retrospective outcome emotions consists of joy, pride, sadness, shame, and anger. This study focuses to investigate the impact three dominance achievement emotions, namely enjoyment, boredom, and anxiety, on three type of cognitive load.

The effect of achievement emotions on cognitive performance were found from various studies. A study from Marchan and Gutierrez (G.C. Marchand, and A.P. Gutierrez,
2011) showed that academic emotion predict the use of learning strategies. Furthermore, hope and anxiety positively predict the use of learning strategies, whereas frustration negatively predict learning strategies both in traditional and online learning group. Academic emotion also affected academic achievement. Enjoyment positively predict academic achievement, but anxiety and boredom negatively predict academic achievement (R. Pekrun, 2006 \& G.C. Marchand, and A.P. Gutierrez, 2011)

Related to the cognitive load, positive emotions negatively predict cognitive load and positive emotions positively predict cognitive load (K. Fraser, et al, 2012). Those findings provide a basis to predict the impact of achievement emotions on cognitive load.

\section{Methods}

\section{A. Participants}

Three hundred and thirty-nine undergraduate students $(73,5 \%$ were female) from various department of Universitas Negeri Semarang, Indonesia, were involved in this survey. All participants participated in statistics class. Their ages ranged from 17 to 24 years old $(\mathrm{M}=19.15, \mathrm{SD}=4,28)$. Before responding the questionnaire, participants were required to express a written consent for participating to the study.Instruments

There are two instruments applied in this study, namely, cognitive load scale and achievement emotion questionnaire. The cognitive load scale was applied to assess participants' cognitive load during learning statistics class and the achievement emotions questionnaire was applied to assess participants' during participate in statistics class.

\section{1) Cognitive load}

The subjective measurement of cognitive load was assessed by applying cognitive load scales which developed by Leppink, Paas, Gog, Vleuten, and Merrienboer (J. Leppink, et al, 2014). The cognitive load scale had 13 items with an 11-point scale from not at all the case (0) to completely the case (10). The first four items are for measuring intrinsic cognitive load, the next four items were for assessing extraneous cognitive load and the last five items were for assessing germane cognitive load. This study showed that the alpha coefficient of reliability ranged between 0.76 0.80 . 


\section{2) Emotions}

Emotions during participate in statistics class were assessed using the achievement emotions scale [18]. A total 21 items were applied to assess enjoyment (5 items), boredom (11 items), and anxiety (5 items). Participants responded each item on 4-point scale ranging from none of the time (0) to all of the time (3). The coefficient alpha of computer emotions scale in the present study ranged from .83 to .93 .

\section{B. Procedures}

The correlational design (J. W. Creswell, 2011) was implemented to investigate the role achievement emotions on cognitive load during classroom learning, particularly statistics class. Data were collected from statistics class. Before statistics class was begun, students were informed that they would be asked to respond scales based on their experience during statistics class at that time. Therefore, all students informed to participate statistics class as usual. Ten minutes before class ends, students are asked to spontaneously respond two scales according to their experience in the class that has just ended. First of all students answered the cognitive load scale, then followed the achievement emotions questionnaire.

\section{Data analysis}

The data were collected from the end of statistics class. Data analysis, namely descriptive analysis, correlation analysis, and hierarchical regression analysis, were implemented to test the prediction of achievement emotions on cognitive load. Students' gender and semester were controlled during test the hypothesis.

\section{Results and Discussion}

\section{A. Descriptive Data}

Table 1 showed the descriptive, inter correlation matrices, and alpha coefficients for each scale. As seen on Table 1, gender had correlation with semester, extraneous load, anxiety and boredom, whereas semester had correlation with intrinsic load, extraneous load, and anxiety. Intrinsic load correlated with extraneous and germane load, but there was no correlation between extraneous load with germane load. Almost type of achievement emotions had correlation with all type of cognitive load.

\section{B. The prediction of academic emotions on cognitive load}

The results of hierarchical regression analysis, as seen on Table 2, showed that after controlling gender and semester all prediction of achievement emotions on all type of cognitive load were significant. However, only a few of achievement emotions success to predict cognitive load. Intrinsic load was positively predicted by enjoyment $(\beta=0.15, \mathrm{p}$ $<0.05)$ and boredom $(\beta=0.18, \mathrm{p}<0.01)$, whereas extraneous load was only predicted by boredom $(\beta=0.38, p<0.01)$. Finally, germane load was predicted by enjoyment $(\beta=0.48, \mathrm{p}<$ $0.01)$ and anxiety $(\beta=0.13, \mathrm{p}<0.05)$. Furthermore, emotions accounted explained $5 \%$, variance of intrinsic load, $18 \%$ variance of extraneous load, and $23 \%$ variance of germane load.

Findings of present study success to clarify the prediction of achievement emotions on cognitive load. Specifically, enjoyment positively predicted germane load and intrinsic load, whereas anxiety only predicted germane load. Moreover, boredom predicted intrinsic and extraneous load. The findings have succeeded to extend the finding of a study from Fraser et al (K. Fraser, et al, 2012; Sunawan, et al, 2017; and Sunawan, \& J. Xiong, 2016). By controlling students' gender and semester, the results of this study confirm certain types of emotions that predict intrinsic, extraneous, and germane load

Findings of present study support the results of study from Chen and Chang [5]. In the study, Chen and Chang showed that anxiety positively predict cognitive load which was assessed as a single construct. Furthermore, finding of present study assert that anxiety positively predict germane load. This finding can be interpreted that, at tolerable level, anxiety encourage students to allocate working memory resources for processing learning contents.

Further, the negative impact of boredom on extraneous and intrinsic load can be explained from concept of attention (E. Awh, et al, 2005; N. Berggren, et al, 2012; K. Vytal, et al, 2012; and C. L. Reeve, et al, 2012) because boredom push to distract working memory from the learning content and replace it by processing information on the source of emotion [26]. In intrinsic load context, boredom signify the learning content as more complex information. 
Consistent with previous study from Sunawan (2017) findings of present study indicated the advantageous consequences of enjoyment for student during learning process. Enjoyment enable learners less distract so that they can implement the effective strategies for problem solving and information processing. The benefit impact of enjoyment on cognitive factor is also relevance with the finding from You and Kang (J.W. You and M. Kang, 2014) which showed that learners with positive emotions tend to implement various strategies which enable them to process learning task information and to ignore the irrelevant learning task information. In such circumstance, enjoyment facilitates students to optimize their germane load.

Table 1. Inter correlation Metrics, Means, Standard Deviation, and Alpha Coefficients

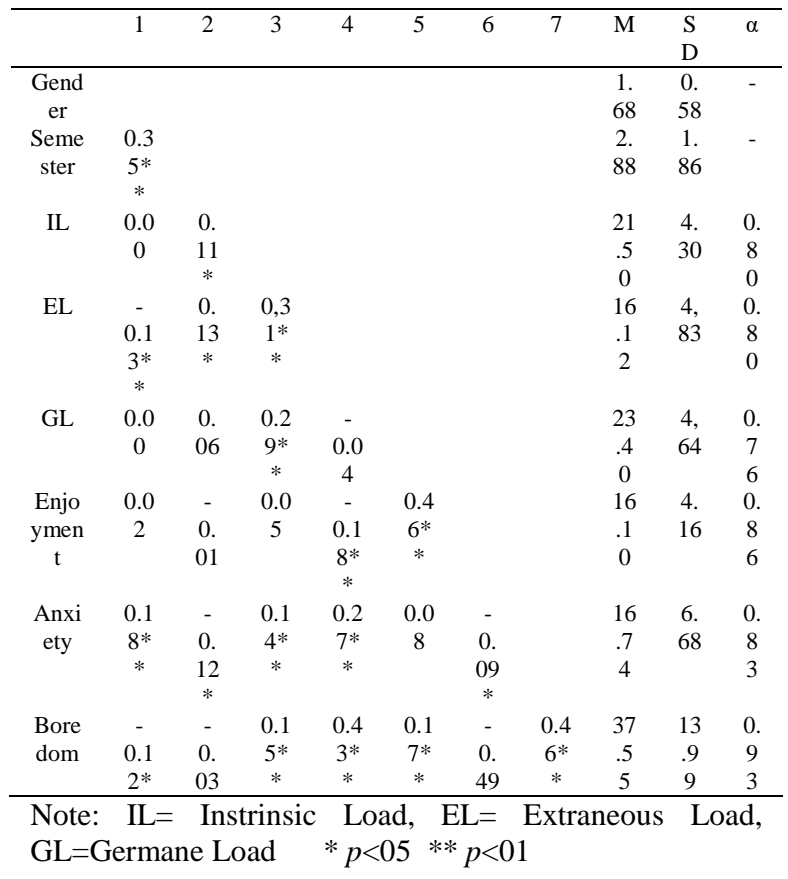

Limitation and Implications Present study succeeded to clarify the role of achievement emotions to cognitive load. Findings of present study specifically showed that enjoyment and anxiety predicted germane load, boredom predicted extraneous load, and enjoyment and boredom predict intrinsic load.

However, the current study had some limitations. First, experiment study should be implemented to test what situation that emotions have effect toward cognitive load. Second, students' learning performance and achievement is not involved in current study. Therefore, further study need to explore the impact of academic emotions on both cognitive load and learning achievement. The practical implications from current findings is that teachers need to improve and manage students' enjoyment during learning so that they allocate most working memory resource for processing learning content.

Table 2. The Regression Analysis Result

\begin{tabular}{|c|c|c|c|c|c|c|}
\hline \multirow{2}{*}{$\begin{array}{l}\text { Predictor } \\
\text { s }\end{array}$} & \multicolumn{2}{|c|}{ Intrinsic Load } & \multicolumn{2}{|c|}{$\begin{array}{c}\text { Extraneous } \\
\text { Load }\end{array}$} & \multicolumn{2}{|c|}{ Germane Load } \\
\hline & $\begin{array}{l}\text { Mod } \\
\text { el } 1\end{array}$ & $\begin{array}{l}\text { Mod } \\
\text { el } 2\end{array}$ & $\begin{array}{l}\text { Mod } \\
\text { el } 1\end{array}$ & $\begin{array}{c}\text { Model } \\
2\end{array}$ & $\begin{array}{l}\text { Mod } \\
\text { el } 1\end{array}$ & $\begin{array}{c}\text { Model } \\
2\end{array}$ \\
\hline Gender & 0.04 & 0.01 & $\begin{array}{c}- \\
0.20^{*} \\
*\end{array}$ & $-0.14 *$ & -0.02 & -0.01 \\
\hline Semester & $\begin{array}{c}0.12 \\
*\end{array}$ & $0.13^{*}$ & $\begin{array}{c}0.20 * \\
*\end{array}$ & $\begin{array}{c}0.20^{*} \\
*\end{array}$ & 0.07 & 0.09 \\
\hline Anxiety & & 0.08 & & 0.10 & & $0.13^{*}$ \\
\hline $\begin{array}{c}\text { Boredo } \\
\mathrm{m}\end{array}$ & & $\begin{array}{c}0.18 * \\
*\end{array}$ & & $\begin{array}{c}0.38 * \\
*\end{array}$ & & 0.01 \\
\hline $\begin{array}{c}\text { Enjoyme } \\
\text { nt }\end{array}$ & & $0.15^{*}$ & & 0.02 & & $\begin{array}{l}0.48^{*} \\
*\end{array}$ \\
\hline$\Delta \mathrm{R}$ & & 0.13 & & 0.25 & & 0.42 \\
\hline$\Delta \mathrm{R}^{2}$ & & 0.05 & & 0.18 & & 0.23 \\
\hline$\Delta \mathrm{F}$ & & $\begin{array}{c}5.51^{*} \\
*\end{array}$ & & $\begin{array}{c}25.84 \\
* *\end{array}$ & & $\begin{array}{c}33.67 \\
* *\end{array}$ \\
\hline $\mathrm{R}$ & 0.11 & 0.24 & 0.23 & 0.48 & 0.07 & 0.49 \\
\hline $\mathrm{R}^{2}$ & 0.01 & 0.06 & 0.05 & 0.23 & 0.00 & 0.24 \\
\hline $\mathrm{F}$ & 2.19 & $\begin{array}{c}4.22 * \\
*\end{array}$ & $\begin{array}{c}5.08^{*} \\
*\end{array}$ & $\begin{array}{c}19.94 \\
* *\end{array}$ & 0.76 & $\begin{array}{c}20.59 \\
* *\end{array}$ \\
\hline
\end{tabular}

\section{Conclusion}

The results of present study showed that achievement emotion predicted cognitive load. Specifically, after controlled gender and students' study period, enjoyment positively predicted germane and intrinsic load, boredom positively predicted intrinsic and extraneous load, whereas anxiety predicted intrinsic and germane load. Findings of present study exert the impact of emotions on cognitive load.

\section{References}

F. Paas, T. Van Gog, and J. Sweller, "Cognitive load theory: New conceptualization, specification and integrated research perspectives," Educational Psychology Reviews, vol. 22, pp. 115-121, 2010.

G.C. Marchand, and A.P. Gutierrez, "The role of emotion in the online learning: 
Comparisons between online and face-toface learning settings," Internet and Higher Education, vol. 15, pp. 150-160, 2012, doi:10.1016/j.iheduc.2011.10.001

Chen and C. Chang, "Cognitive load theory: An empirical study of anxiety and task performance in language learning," Electronic Journal of Research in Educational Psychology, vol. 7, no. 2, pp. 729-746, 2009.

J.W. Creswell, Educational Research: Planning, Conducting, and Evaluating Quantitative and Qualitative Research, 5th ed., Boston, MA: Pearson. 2011.

J. Leppink, F. Paas, T. vanGog, T., C.P.M. Vleuten, and J.J.G. Merrienboer, "Effects of pairs of problems and examples on task performance and different types of cognitive load," Learning and Instruction, vol. 30, pp. 32-42, 2014.

J. Sweller, "Implications of cognitive load theory for multimedia learning," in The Cambridge Handbook of Multimedia Learning, R.E. Mayer, Ed, New York, NY: Cambridge University Press, 2005.

J. Sweller, "Element interactivity and intrinsic, extraneous and germane cognitive load," Educational Psychology Review, vol. 22, pp. 123-138, 2010a.

J. Sweller, "Cognitive load theory: Recent theoretical advances," in Cognitive Load Theory, J.L. Plass, R. Moreno, \& R. Brunken, eds., Cambridge: Cambridge University Press, 2010b, pp. 29-47.

J.W. You and M. Kang, "The role of academic emotions in the relationship between perceived academic control and selfregulated learning in online learning," Computer and Education, vol. 77, pp. 125-133, 2014.

K. Fraser, I. Ma, E. Teteris, H. Baxter, B. Wright, and K. McLoughlin, "Emotions, cognitive load, and learning outcomes during simulation training," Medical Education, vol. 46, pp. 1055-1062, 2012.

M.J. Jacobson, "A design framework for educational hypermedia systems: Theory, research, and learning emerging scientific conceptual perspectives," Education
Technology Research Dev., vol. 56, pp. 528, 2008.

N. Berggren, E.H.W. Koster and N. Derakshan, "The effect of cognitive load in emotional attention and trait anxiety: An eye movement study," Journal of Cognitive Psychology, vol. 24, no. 1, pp. 79-91. 2012. doi: 10.1080/20445911.2011.618450.

R. Brunken, J.L. Plass, and R. Moreno, "Current issues and open questions in cognitive load research," in Cognitive Load Theory, J.L. Plass, R. Moreno, and R. Brunken, eds, Cambridge: Cambridge University Press, 2010.

R.C. Clark, F. Nguyen, and J. Sweller, J, Efficiency in Learning: Evidence-based Guidelines to Manage Cognitive Load, San Francisco, CA: Pfeiffer, 2006.

R. Pekrun, "The control-value theory of achievement emotions: Assumptions, corollaries, and implications for educational research and practice," Educational Psychology Reviews, vol. 18, no. 3, pp. 315-341, 2006.

S. Chen and J. Epps. "Automatic classification of eye activity for cognitive load measurement with emotion interference," Computer Methods and Programs in Biomedicine, vol. 11, pp. 111-124, 2013.

S. Lichtenfeld, R. Pekrun, R.H. Stupnisky, K. Reiss, and K. Murayama, "Measuring students' emotions in the early years: The achievement emotions questionnaireelementary school (AEQ-ES)," Learning and Individual Differences, vol. 22, pp. 190-201, 2012.

Sunawan, S.Y.A. Yani, T.I. Kencana, C.T. Anni, Mulawarman, \& A. Sofyan. "Dampak efikasi diri terhadap beban kognitif dengan emosi akademik sebagai mediator," Jurnal Psikologi. vol. 44, no. 1, pp. 28-38, 2017.

Sunawan, \& J. Xiong. "The prediction of academic emotions on cognitive load in hypermedia learning environment" Advance in Economics, Business, and Management Research, vol. 14, pp. 378383, 2016. 